\title{
COMPLEJIDAD DE LA EXPRESIÓN DE GENES ASOCIADOS A OBESIDAD EN EL TEJIDO ADIPOSO HUMANO
}

\author{
ALEJANDRA RODRÍGUEZ BS.C. ${ }^{1}$, CARLOS ECHANDÍA PhD. ${ }^{2}$, ADALBERTO SÁNCHEZ PhD. ${ }^{1}$, \\ JOSÉ MARÍA SATIZÁBAL PhD. ${ }^{1}$, JULIO CÉSAR MONTOYA PhD ${ }^{1}$, FELIPE GARCÍA VALLEJO PhD. ${ }^{1}$ \\ ${ }^{1}$ Departamento de Pediatría. Escuela de Medicina. Facultad de Salud. Universidad del Valle. Cali, Colombia. \\ ${ }^{2}$ Laboratorio de Biología Molecular y Patogénesis. Departamento de Ciencias Fisiológicas. \\ Escuela de Ciencias Básicas. Facultad de Salud. Universidad del Valle. Cali, Colombia. \\ Correspondencia: Alejandra Rodríguez Bs. C. Bióloga. Estudiante de Doctorado en Ciencias Biomédicas. Escuela \\ de Ciencias Básicas. Facultad de Salud. Universidad del Valle. alejandra.rodriguez@correounivalle.edu.co
}

Recibido: 13 de junio de 2017 Aceptado: 31 de octubre de 2017

\begin{abstract}
Resumen
Objetivo: analizar la complejidad de la expresión génica en tejido adiposo de genes asociados con obesidad, mediante simulación computacional con diferentes herramientas bioinformáticas. Métodos: después de una búsqueda bibliográfica en PubMed, se seleccionaron 37 genes asociados con obesidad con fold change mayor a 1,5. A partir del cálculo de valores de los z-score obtenidos de experimentos de micromatrices de ADN de muestras de tejido adiposo de personas obesas y de control, se construyó una red de interacción con el programa Cytoscape 3.2. La información detallada sobre las características genómicas de estos genes se extrajo de las bases de datos Genome Browser de la UCSC y del NCBI. Utilizando herramientas de análisis de multivariado, se hizo un análisis de componentes principales y uno de agrupación. Resultados: la red construida mostró que los genes con mayor número de interacciones fueron: 1) el factor nuclear respiratorio (NRF1), 2) el canal activado de potasio activado por calcio alfa 1 (KCNMA1) y 3) la sintasa de ácidos grasos (FASN). Los que tuvieron mayores valores de expresión fueron: 1) el factor de crecimiento endotelial vascular A (VEGFA), 2) la dioxigenasa dependiente de alfa-cetoglutarato (FTO) y 3) el regulador de crecimiento neuronal 1 (NEGR1). Las proteínas IL6, BDNF y HLC tuvieron los mayores valores de interacción con IL6R, NRF1 y ACACB, respetivamente. Las categorías ontológicas más importantes se relacionaron con procesos metabólicos de lipoproteínas, el ciclo de los ácidos tricarboxílicos, la activación de las MAP-quinasas y la cascada JNK. Conclusiones: en su conjunto los resultados obtenidos de sobreexpresión diferencial de genes asociados con el metabolismo de lípidos en el tejido adiposo de personas obesas podría ser un criterio para discriminar a nivel de diagnóstico esta patología.
\end{abstract}

Palabras clave: obesidad; tejido adiposo; expresión génica; micromatrices de ADN; bioinformática.

\section{COMPLEXITY OF THE EXPRESSION OF GENES ASSOCIATED WITH OBESITY IN HUMAN ADIPOSE TISSUE}

Running title: Global gene expression in human adipose tissue

\section{Summary}

Objective: to analyze the complexity of gene expression in the adipose tissue of genes associated with obesity, by computer simulation with different bioinformatics tools. Methods: after conducting a PubMed literature search, 37 genes associated with obesity with a fold change greater than 1.5 were selected. An interaction network was cons- 
tructed using the Cytoscape 3.2 program from the calculation of z-score values obtained from DNA microarray experiments of adipose tissue samples collected from obese and control people. Detailed information on the genomic characteristics of these genes was extracted from the UCSC and NCBI Genome Browser databases. Using multivariate analysis tools, a principal component analysis and a cluster analysis were carried out. Results: the constructed network showed that the genes with the greatest number of interactions were: 1) the nuclear respiratory factor (NRF1), 2) the activated channel of potassium activate by calcium alpha 1 (KCNMA1), and 3) the fatty acid synthase (FASN). Those with the higher expression values were: 1) vascular endothelial growth factor A (VEGFA), 2) alpha-ketoglutaratedependent dioxygenase (FTO), and 3) neuronal growth regulator 1 (NEGR1). The IL6, BDNF and HLC proteins had the highest interaction values with IL6R, NRF1 and ACACB, respectively. The most important ontological categories were related to lipoprotein metabolic processes, the tricarboxylic acid cycle, the activation of the MAP kinases, and the JNK cascade. Conclusions: As a whole, the results obtained from differential overexpression of genes associated with lipid metabolism in the adipose tissue of obese people could be a criterion to discriminate this pathology at a diagnostic level.

Keywords: Obesity; Adipose tissue; Gene expression; DNA microarrays; Bioinformatics.

\section{COMPLEXIDADE DA EXPRESSÃO DE GENES ASSOCIADOS À OBESIDADE NO TECIDO ADIPOSO HUMANO}

\section{Resumo}

Objetivo: analisar a complexidade da expressão gênica no tecido adiposo de genes associados com obesidade, por meio de simulação por computador com diferentes ferramentas bioinformáticas. Métodos: após uma busca bibliográfica em PubMed, foram selecionados 37 genes associados com obesidade com fold change superior a 1,5. A partir do cálculo de valores dos z-score obtidos de experimentos de micro matrizes de ADN de amostras de tecido adiposo de pessoas obesas e de controle, construiu-se uma rede de interação com o programa Cytoscape 3.2. A informação detalhada sobre as características genômicas destes genes foi obtida das bases de dados Genome Browser da UCSC e do NCBI. Utilizando ferramentas de análise de multivariado, fez-se uma análise de componentes principais e um de agrupação. Resultados: a rede construída mostrou que os genes com maior número de interações foram: 1) o fator nuclear respiratório (NRF1), 2) o canal ativado de potássio ativado por cálcio alfa 1 (KCNMA1) e 3) ácido graxo sintase (FASN). Os que tiveram maiores valores de expressão foram: 1) o fator de crescimento endotelial vascular A (VEGFA), 2) a dioxigenase dependente de alfa-cetoglutarato (FTO) e 3) o regulador de crescimento neuronal 1 (NEGR1). As proteínas IL6, BDNF e HLC tiveram os maiores valores de interação com IL6R, NRF1 e ACACB, respectivamente. As categorias ontológicas mais importantes se relacionaram com processos metabólicos de lipoproteínas, o ciclo dos ácidos tri carboxílicos, a ativação das MAP-quinases e a cascata JNK. Conclusões: Em seu conjunto, os resultados obtidos de superexpressão diferencial de genes associados com o metabolismo de lipídios no tecido adiposo de pessoas obesas poderia ser um critério para discriminar a nível de diagnóstico esta patologia.

Palavras-chave: Obesidade; Tecido adiposo; Expressão gênica; Micro matrizes de ADN; Bioinformática.

\section{Introducción}

La obesidad es una condición de salud compleja que, generalmente, se asocia con desórdenes metabólicos como la diabetes y el daño cardiovascular, entre otros; se caracteriza por la acumulación de grasa corporal, producida por un desbalance entre las calorías ingeridas y las eliminadas (1,2). Estudios epidemiológicos han mostrado de manera consistente que ciertas dietas y estilos de vida acentúan el riesgo de obesidad. En este sentido, existe evidencia que el consumo continuo de bebidas azucaradas (3-5), alimentos fritos (6), baja actividad física o sedentarismo (7), interactúan con ciertas variantes génicas en la asociación con la obesidad. 
Desde mediados del siglo pasado, la obesidad y el sobrepeso se han convertido en un gran estigma en la mayoría de los países del mundo. Por su parte, la Organización Mundial de la Salud (OMS) la considera una enfermedad dependiendo del lugar del mundo donde se presenta (8). Reportes previos documentan que la obesidad en el mundo se ha duplicado desde 1980. Así pues, en 2014 se estimaba que más de 1,9 millones de adultos mayores de dieciocho años tenían sobrepeso y, de estos, 600 millones eran obesos. Más preocupante todavía es que aproximadamente 41 millones de niños menores de cinco años eran obesos principalmente en países desarrollados (9). Ahora bien, tanto el manejo y como tratamiento de la obesidad son difíciles debido a su naturaleza multifactorial, pues depende de factores genéticos, epigenéticos, ambientales y, también importante, de aspectos socioeconómicos (10-14).

La complejidad de la obesidad se refleja en que el aprendizaje y los hábitos generan estimulación en diferentes áreas del cerebro, cuya respuesta promueve un incremento de la captación de energía y el consecuente aumento de la masa corporal. En estos procesos, el hipocampo y la amígdala están involucrados en el control de señales internas de hambre, memoria y los procesos inhibitorios relacionados con la ingesta alimentaria (15). Diferentes líneas de evidencia sugieren la existencia de una correlación entre la función del sistema dopaminérgico con marcadores de obesidad durante su progresión (16). Se postula que tanto procesos de neuroplasticidad como diferentes endofenotipos individuales estarían jugando un papel importante en el sobrepeso moderado y en la obesidad severa (17).

El tejido adiposo juega un papel importante en muchas de las condiciones patológicas asociadas con la obesidad, actuando como un órgano endocrino integral en la regulación de la homeóstasis energética, la sensibilidad a la insulina y la tolerancia a la glucosa $(18,19)$. Adicionalmente al adipocito, el tejido adiposo blanco contiene pre-adipocitos, células endoteliales, fibroblastos y leucocitos (20). En la condición de obesidad, el número de leucocitos del tejido adiposo se incrementa dramáticamente, promoviendo un estado crónico de un bajo grado de inflamación (21). En este estado, los leucocitos activados, macrófagos y células $T$ secretan interleukina-1 (IL-1), interleukina-6 (IL-6), y factor de necrosis tumoral $\alpha$ (TNF $\alpha)$, que son citosinas inflamatorias $(22,23)$.

El acelerado desarrollo de las ciencias ómicas en el último decenio ha contribuido a un mayor conocimiento de enfermedades complejas como la obesidad. Los análisis de expresión global de genes a partir de experimentos de micromatrices de ADN y de análisis poblacionales de genomas han permitido comenzar a reconocer aspectos dinámicos de la regulación de la expresión de tejido específica de genes y las complejas redes de interacción en diferentes patologías (24-27). En este contexto, el estudio de transcriptomas ha hecho posible abordar la relación entre la expresión global de genes en el tejido adiposo con la obesidad y sus patologías asociadas. Durante la restricción calórica, la adipogénesis y la síntesis de ácidos grasos insaturados se asocia con cambios metabólicos en esta condición (28). Se ha demostrado la asociación de la actividad de la stearoil-CoA desaturasa 1 y los índices de saturación de ácidos grasos en tejido adiposo con la resistencia a insulina en la obesidad (29).

Varios estudios en torno a la obesidad han enfocado sus esfuerzos en encontrar biomarcadores asociados con esta enfermedad que sean útiles en la identificación temprana de individuos susceptibles y puedan agregar valor al riesgo atribuible de desarrollar patologías asociadas (30-32).

Este estudio tuvo como objetivo la analizar la complejidad de expresión de genes asociados con obesidad en el tejido adiposo blanco de personas obesas. El punto de partida de los análisis consignados en este trabajo fueron los valores de expresión global de genes consignados en diferentes experimentos de micromatrices de ADN de genes asociados con diferentes procesos metabólicos y fisiológicos, característicos de la obesidad. Para ello, se realizó una búsqueda bibliográfica en PubMed, en la cual se seleccionaron 37 genes asociados a obesidad, con fold change mayor a 1,5. A partir del cálculo de valores z-score obtenidos de estas micromatrices de ADN, se evaluó la complejidad de la expresión de estos genes. Se construyó una red de interacción génica y se aplicaron pruebas de estadística multivariada, que incluyeron un Análisis de Agrupación y uno Análisis de Componentes Principales. En conjunto, los resultados mostraron que existe una sobreexpresión diferencial de ciertos genes en el tejido adiposo de personas obesas.

\section{Materiales y métodos}

En primer lugar, se seleccionaron 39 artículos pertinentes al tema de investigación, publicados entre 2010 y 2016, luego de una búsqueda en la base de datos bibliográficos PubMed del Centro Nacional para la Información Biotecnológica (NCBI). La búsqueda se llevó a cabo usando 
los siguientes descriptores: obesidad, tejido adiposo, expresión génica, micromatrices de $\mathrm{ADN}, \log >1,5$ y valor $p<0,05$. De los artículos seleccionados, se obtuvo información genómica y funcional correspondiente a los siguientes 37 genes que se asociaron con obesidad y algunas de sus patologías asociadas: ANGPTL4, ADIPOQ, ACACB, ELOVL6, LPL, VEGFA, TNMD, MMP9, FTO, SCD, FASN, NEGR1, TMEM18, MAF, MTCH2, LEP, C9orf116, IL6, PPARGC1A, SOD2, IRAK3, IPO8, KDM2B, ITIH5, KCNMA1, MEDAG, ADCY3, MC4R, BDNF, SH2B1, SULT1A2, HMGCR, NPC1, IGF1, NOS3, NRF1 y KEAP1. Todos ellos tuvieron valores fold change mayores de 1,5 y valores $\mathrm{P}$ menores de 0,05.

Las descripciones y características generales de los genes incluidos en este estudio se obtuvieron del Genome Browser de la Universidad de California en Santa Cruz (UCSC). Estas incluyeron el locus cromosómico, el número de exones, el tamaño del gen en pares de bases y su respectivo ARNm en nucleótidos y el total de genes y de repeticiones en el cromosoma correspondiente. Asimismo, se calculó un índice de complejidad de cada gen, aplicando la relación entre el tamaño del ARNm y el tamaño de su gen codificante (Suplemento 1).

A partir de la información correspondiente de las diferentes bases de datos de acceso libre del Genome Browser y del Map Viewer del NCBI se realizó un paseo cromosómico en las zonas $100 \mathrm{Kpb}$ upstream y downstream para cada uno de los genes incluidos en este estudio, calculando el número de secuencias repetidas Alu, islas $\mathrm{CpG}$ y genes.

Para analizar la expresión de los genes seleccionados y asociados con obesidad, se tomaron los datos de un trabajo depositado por Oñate y colaboradores (25), en la base de datos de acceso libre Gene Expression Omnibus del NCBI. El experimento de micromatrices se $\mathrm{ADN}$, base de este estudio, está registrado bajo el número de plataforma GPL6244, serie GSE48964 que incluye muestras de pacientes con obesidad mórbida (códigos GSM1187673, GSM1187674 y GSM1187675) y muestras control de personas no obesas (códigos GSM1187676, GSM1187677, GSM1187678). De acuerdo con lo reportado en 2013 por Oñate y su equipo, el ARN total de las muestras, se extrajo de cultivos de células troncales derivadas de tejido adiposo blanco subcutáneo de personas obesas que se habían sometido a intervenciones bariátricas.
Los valores $\log >2,0$ consignados en la plataforma GPL6244, serie GSE48964, para cada uno genes asociados a obesidad incluidos en este trabajo, se normalizaron por medio de la transformación zscore de acuerdo con la siguiente ecuación.

$$
\text { z-score }=\frac{(\log \text { intensity of } G-\text { mean } \log \text { intensity } G \ldots G n)}{\text { standard deviation } \log G \ldots G n}
$$

Los valores z-score calculados para cada gen se emplearon en la construcción de una red de interacción de genes, por medio de la plataforma Cytoscape 3.2, que es de acceso libre (sitio web: www.cytoscape.org/download.php) (33). Los valores de los diferentes parámetros topológicos de la red obtenida se extrajeron por medio de la función Network A nalyzer. La información acerca de las interacciones físicas de mayor peso entre los genes evaluados asociados con obesidad se extrajo por medio de la interfase Web GeneMANIA. Esta información se complementó con la contenida en la base de datos Biological General Repository for Interaction Datasets (BioGRID) y en la plataforma Protein Interaction Network Analysis platform PINA2. Los valores p estadísticamente significativos obtenidos, luego de aplicar la corrección por técnica de ajuste secuencial de Bonferroni para las primeras 20 categorías ontológicas (GO, por sus siglas en inglés), fueron extraídos utilizando el plugin Biological Networks Gene Ontology tool (BiNGO) de la plataforma Cytoscape 3.2.

Con el fin de jerarquizar la expresión de cada uno de los genes en los dos grupos evaluados, se efectuó la evaluación de su significancia estadística mediante pruebas de estadística multivariable incluyendo un Análisis de Componentes Principales (ACP), llevado a cabo con el programa SPSS 20.0. Para visualizar las agrupaciones diferenciales de aquellos genes con mayor o menor expresión en tejido adiposo de personas obesas y del grupo control, se efectuó un análisis de agrupación obteniendo mapas de calor Heat-Map, disponible en la misma plataforma Cytoscape 3.2.

\section{Resultados}

En la red construida se observaron dos nodos principales, con cantidad significativamente alta de interacciones: el más grande tiene como centro la proteína NRF1 (figura 1). Además, se destacaron por su elevada expresión los genes que codifican para VEGFA (z-score 2,02), 


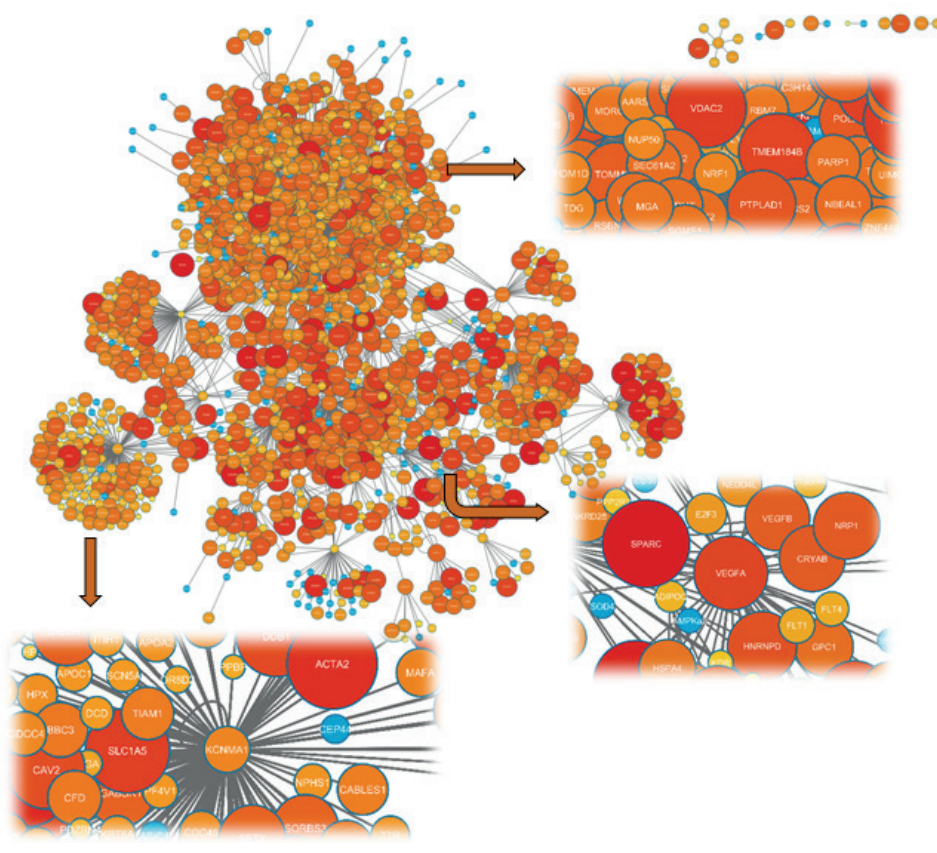

Figura 1. Red de interacción y expresión de proteínas codificadas por genes asociados con obesidad, obtenida por medio del software Cytoscape 3.2. La expresión de los genes proviene de células troncales del tejido adiposo blanco de personas obesas, tomadas del estudio de Oñate y colaboradores (25). Se resaltan los nodos KCNMA 1, NRF1 y VEGFA. EI color rojo indica mayor expresión y el amarillo, menor.

FTO (z-score 1,31), NEGR1 (z-score 0,88), MTCH2 (zscore 1,57$)$, IL6 (z-score 2,15$)$ y NPC1 (z-score 1,25$)$. De los valores de interacción obtenidos de la red de genes asociados con obesidad, la proteína que codifica el gen factor respiratorio nuclear 1 (NRF1) fue la que obtuvo mayor número de interacciones, en total 908; seguida por el canal activado por potasio de la subfamilia $\mathrm{M}$ alfa (1KCNMA1), con 140 interacciones; $y$, en tercer lugar, el ácido grado (FASN) con 127 interacciones (figura 2). Se determinó que los pares de interacciones físicas con mayor peso ocurrieron en los genes asociados con obesidad interleukina-6 (IL6) y su receptor IL6R (peso de $2,9269)$ y entre el factor nuclear respiratorio 1 (NRF1) y el Factor Neurotrópico Derivado del Cerebro BDNF (peso de 2,5247). Los datos se presentan en la tabla 1. Se agrega que se encontraron otras reacciones de importancia como entre NOSTRIN y NOS3 y LEP con HK3.

Los valores de los parámetros topológicos de la red mostraron una topología compleja que se aglutina: el número total de nodos fue de 1744 y el número promedio de vecinos de cada nodo de 2 214. El valor de centralización
Tabla 1. Valores de peso de los pares de interacciones físicas de proteínas codificadas por genes asociados con obesidad, empleando la interfase GeneMA NíA .

\begin{tabular}{|c|c|c|}
\hline Gen 1 & Gen 2 & Peso \\
\hline IL6R & IL6 & 2,9269 \\
\hline NRF1 & BDNF & 2,5247 \\
\hline HLCS & $A C A C B$ & 2,4329 \\
\hline CACNA1H & KCNMA1 & 2,4048 \\
\hline APOC2 & LPL & 2,1458 \\
\hline KIAA0319 & $\mathrm{SH} 2 \mathrm{~B} 1$ & 2,0400 \\
\hline IGFBP5 & IGF1 & 1,7970 \\
\hline USP36 & SOD2 & 1,641 \\
\hline ATRNL1 & MC4R & 1,6413 \\
\hline ADIPOR2 & ADIPOQ & 1,6288 \\
\hline NTM & NEGR1 & 1,4676 \\
\hline NOSTRIN & NOS3 & 1,4672 \\
\hline PPRC 1 & NRF1 & 1,4633 \\
\hline KDR & VEGFA & 1,4621 \\
\hline OSBPL5 & NPC 1 & 1,4303 \\
\hline IRAK1 & IRAK3 & 1,4267 \\
\hline LSAMP & NEGR1 & 1,3994 \\
\hline LSAMP & NTM & 1,3994 \\
\hline HK3 & LEP & 1,38236581 \\
\hline LCN2 & MMP9 & 1,3542 \\
\hline
\end{tabular}

de la red fue significantemente alto: 0,52 , lo que indica que la red, en su mayoría, está centrada en uno de los nodos. En este caso, el gen nodal es NRF1, como se muestra en la tabla 2. 


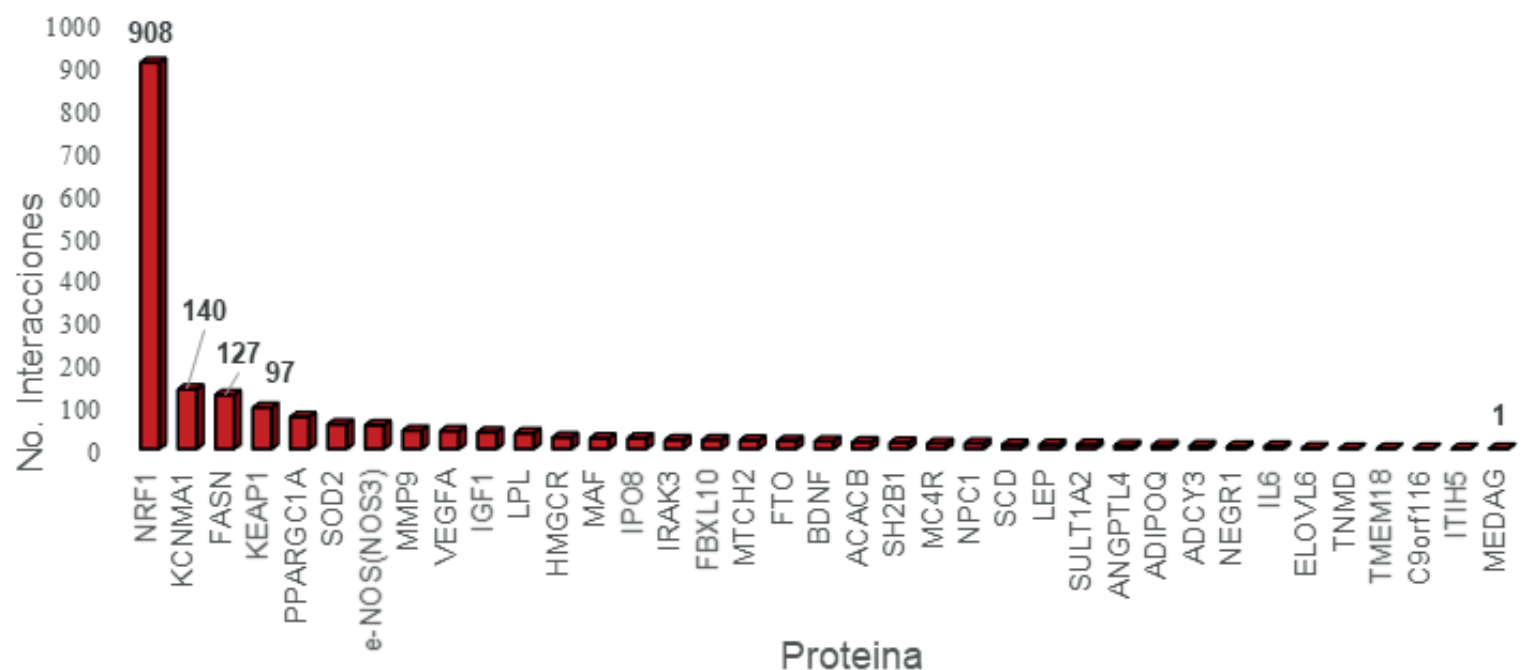

Figura 2. Número de interacciones proteicas encontradas de las proteínas asociadas con obesidad evaluadas en este estudio, obtenidas a partir de las bases de datos de BIOGrid y PINA2. La proteína NRF1 presentó la mayor cantidad de interacciones (908).

Tabla 2. Datos topológicos de la red construida con Cytoscape 3.2, tomando como base los valores de expresión de 37 genes asociados con obesidad de células troncales de tejido adiposo blanco de individuos con obesidad mórbida.

\begin{tabular}{|l|c|}
\hline \multicolumn{1}{|c|}{ Parámetros topológicos } & Valor \\
\hline Coeficiente de agrupamiento & 0,032 \\
\hline Componentes conectados & 42 \\
\hline Diámetro de la red & 8 \\
\hline Radio de la red & 1 \\
\hline Centralización de la red & 0,52 \\
\hline Número promedio de vecinos & 2,214 \\
\hline Número de nodos & 1744 \\
\hline Densidad de la red & 0,001 \\
\hline Heterogeneidad de la red & 10,165 \\
\hline Nodos aislados & 0 \\
\hline
\end{tabular}

En cuanto a las categorías ontológicas (GO) extraídas de la red se destacaron procesos biológicos muy relacionados con eventos patológicas ligados a la obesidad. Entre estos cabe resaltar 1) el proceso metabólico de lipoproteínas, 2) el ciclo de los ácidos tricarboxílicos, 3) la activación de las MAP-quinasas, 4) la cascada JNK y 5) la acumulación de células $T$, como se muestra en la tabla 3. El número de dinucleótidos $\mathrm{CpG}$ en la región de $10 \mathrm{Kpb}$ de la zona upstream fue mucho más alto, en comparación no solo con la zona $10 \mathrm{Kpb}$ downstream sino también con el resto de las zonas. El número de secuencias Alu y de genes fue muy similar en todos los genes analizados durante el paseo cromosómico realizado (figura 3).

El ACP permitió reducir a 2 componentes los 37 genes evaluados en ambos grupos. Se pudo establecer estadísticamente que la contribución de la varianza de los genes asociados con obesidad en los dos componentes fue diferente entre personas obesas y el grupo de control. En los primeros, el componente 1 incluyó 21 genes, de los cuales ACACB, HMGR, IRAK3, ITH5, KDM2B, KEAP1, MAF, NFR1 y C9orf116 fueron los que tuvieron mayores valores de contribución a la varianza. Lo anterior, en contraste con el componente 2, que incluyó 11 genes de los cuales IL6, IPO8, LEP, ADCY3, AGPTL4, BDNF, FASN, FTO y KCMF1 presentaron mayores valores de contribución a la varianza total del componente. El gráfico biplot mostró que existen agrupaciones diferenciales 
Tabla 3. Las veinte principales categorías ontológicas extraídas de la red de obesidad y sus respectivos valores de p obtenidos con la corrección por técnica de ajuste secuencial de Bonferroni. Los valores de p se obtuvieron ejecutando la aplicación con el plugin BiNGO de Cytoscape 3.2.

\begin{tabular}{|c|l|c|}
\hline G.O-ID & \multicolumn{1}{|c|}{ Descripción } & valor p (Bonferroni) \\
\hline 43170 & Proceso metabólico de lipoproteínas & $1,82 \mathrm{E}-25$ \\
\hline 44260 & Ubiquitinización de proteínas & $2,31 \mathrm{E}-25$ \\
\hline 48518 & Regulación positiva del proceso apoptótico & $2,99 \mathrm{E}-23$ \\
\hline 48519 & Regulación negativa de la actividad lipasa & $1,24 \mathrm{E}-20$ \\
\hline 44237 & Ciclo de los ácidos tricarboxílicos & $5,36 \mathrm{E}-20$ \\
\hline 48522 & Señalización de la vía apoptótica intrínseca & $2,98 \mathrm{E}-19$ \\
\hline 9987 & Regulación negativa de la proliferación de células T & $6,86 \mathrm{E}-19$ \\
\hline 48523 & Silenciamiento cromatínico dependiente de metilación & $8,39 \mathrm{E}-19$ \\
\hline 19222 & Regulación negativa de la actividad de la quinasa JUN & $1,37 \mathrm{E}-18$ \\
\hline 60255 & Activación de la MAPK & $5,82 \mathrm{E}-18$ \\
\hline 44238 & Proceso metabólico del colesterol & $1,02 \mathrm{E}-17$ \\
\hline 9893 & Regulación positiva de la cascada JNK & $1,93 \mathrm{E}-17$ \\
\hline 50789 & Regulación de la absorción intestinal de colesterol & $3,53 \mathrm{E}-17$ \\
\hline 51246 & Regulación negativa de la actividad de endopeptidasas & $6,12 \mathrm{E}-17$ \\
\hline 31325 & Regulación positiva de la oxidación de ácidos grasos & $6,54 \mathrm{E}-17$ \\
\hline 42221 & Respuesta celular de lipopolisacáridos & $5,13 \mathrm{E}-16$ \\
\hline 80090 & Regulación del proceso metabólico de lipoproteínas & $5,82 \mathrm{E}-16$ \\
\hline 8152 & Proceso catabólico de lípidos & $9,27 \mathrm{E}-16$ \\
\hline 9892 & Regulación negativa de la gluconeogénesis & $1,50 \mathrm{E}-15$ \\
\hline 65007 & Homeóstasis del colesterol & $\mathrm{E}-15$ \\
\hline & & \multicolumn{1}{|c|}{ (16 } \\
\hline
\end{tabular}

de coexpresión entre personas obesas y las del grupo de control. En personas obesas se observó un grupo conformado por LEP, KCMF1, ITH55, FASN, MAF e IRAK3; diferente al del grupo de control, que incluyó a los genes FTO, SCD, ADPQ, SHB e IPO8 (figura 4).

En el Heat Map (mapa de calor), el análisis de agrupación reveló agrupaciones en dos diferentes bloques. El gen IL6 se encontró expresado diferencialmente, con mayor expresión en personas obesas, en comparación con el grupo de control (figura 5). Es también de gran importan- cia resaltar los genes VEGFA, SOD2, SCD, KCNMA1 y FTO, los cuales están altamente expresados en personas obesas. En general estos genes están involucrados en los procesos de angiogénesis, control del índice de masa corporal (IMC) y metabolismo.

\section{Discusión}

La evidencia obtenida de los análisis desarrollados en este trabajo permite asociar los genes IL6, NFR1, VEGFA, y FTO con la fisiopatología de la obesidad. Un re- 


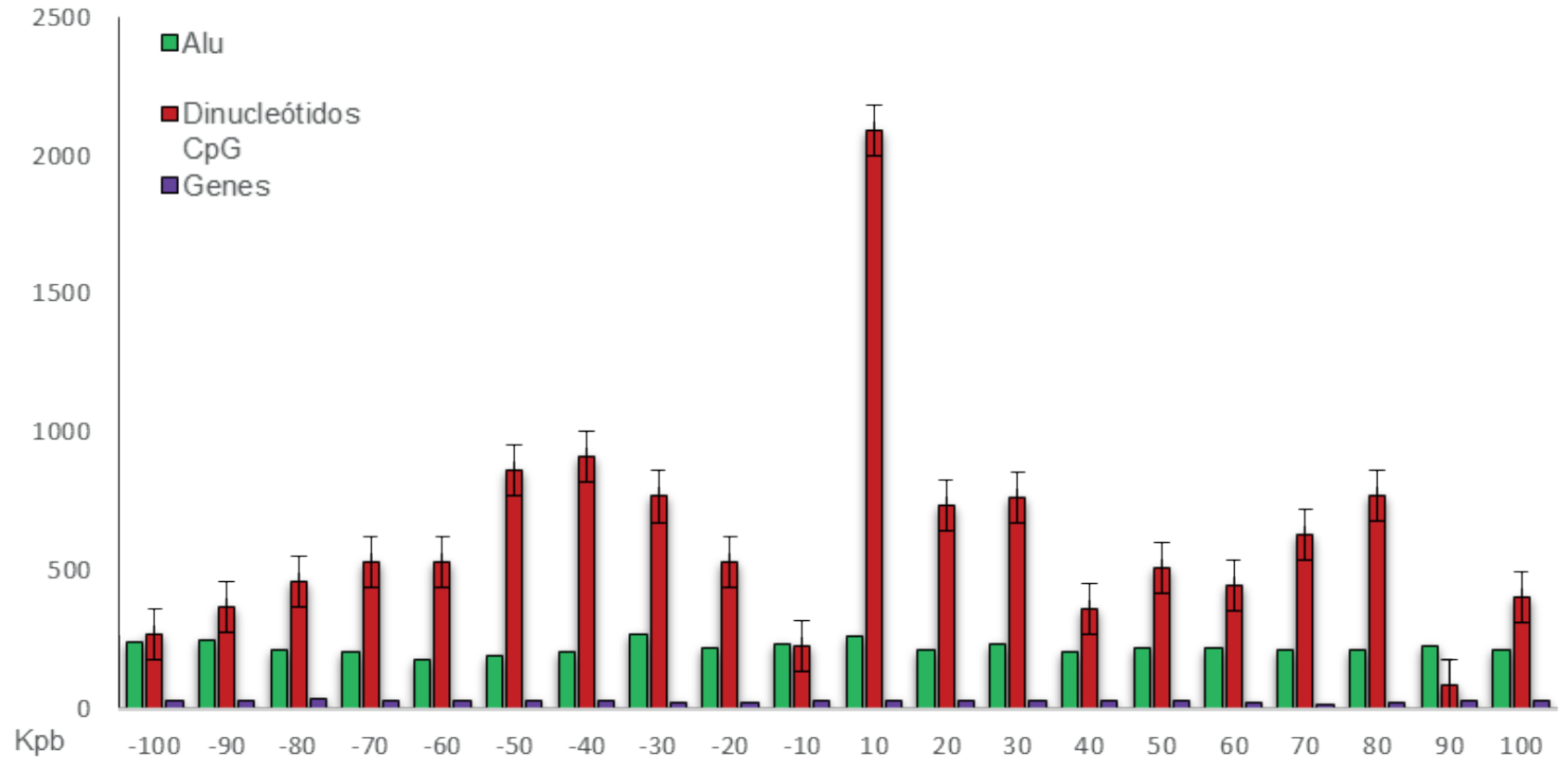

Figura 3. Paseo cromosómico realizado en una ventana de $100 \mathrm{Kpb}$, rodeando cada uno de los 37 genes evaluados, tanto corriente arriba como corriente abajo. Se tomaron en cuenta secuencias repetidas A lu, islas CpG y genes, con pasos de $10 \mathrm{Kpb}$ utilizando información del Genome Browser de la UCSC y del Map Viewer del NCBI.

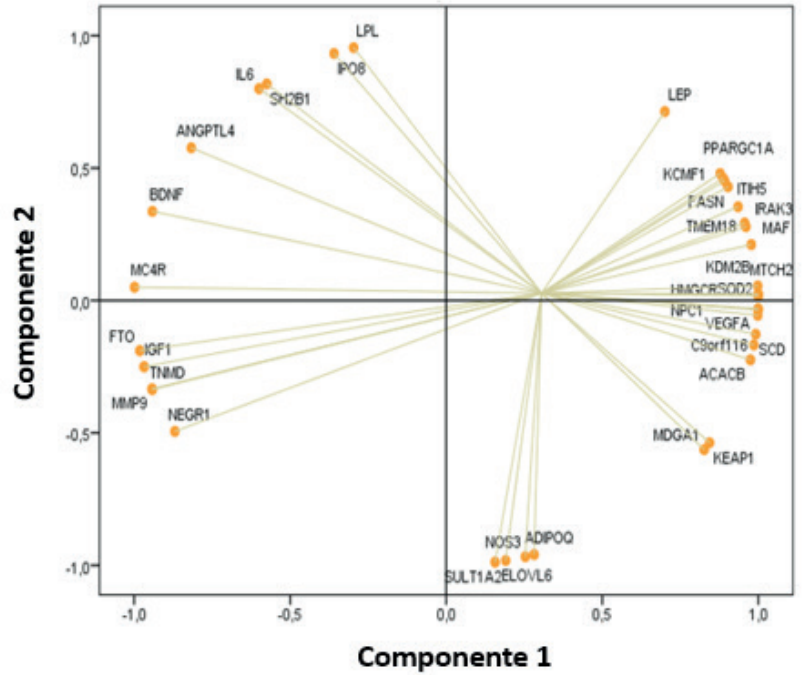

Grupo Obesidad

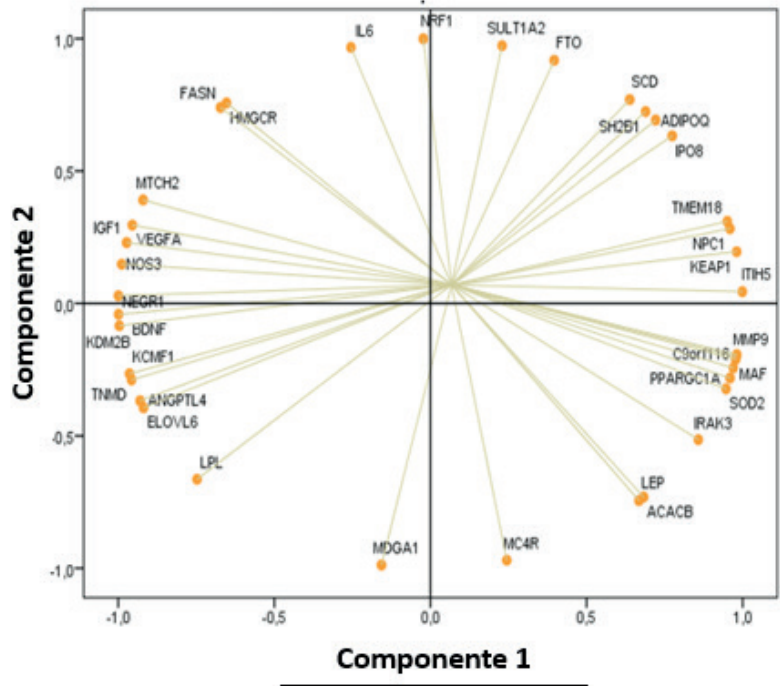

Grupo Control

Figura 4. Gráficos Biplot del análisis de componentes principales para los grupos de obesidad y control, obtenidos con el programa SPSS V22.0. 


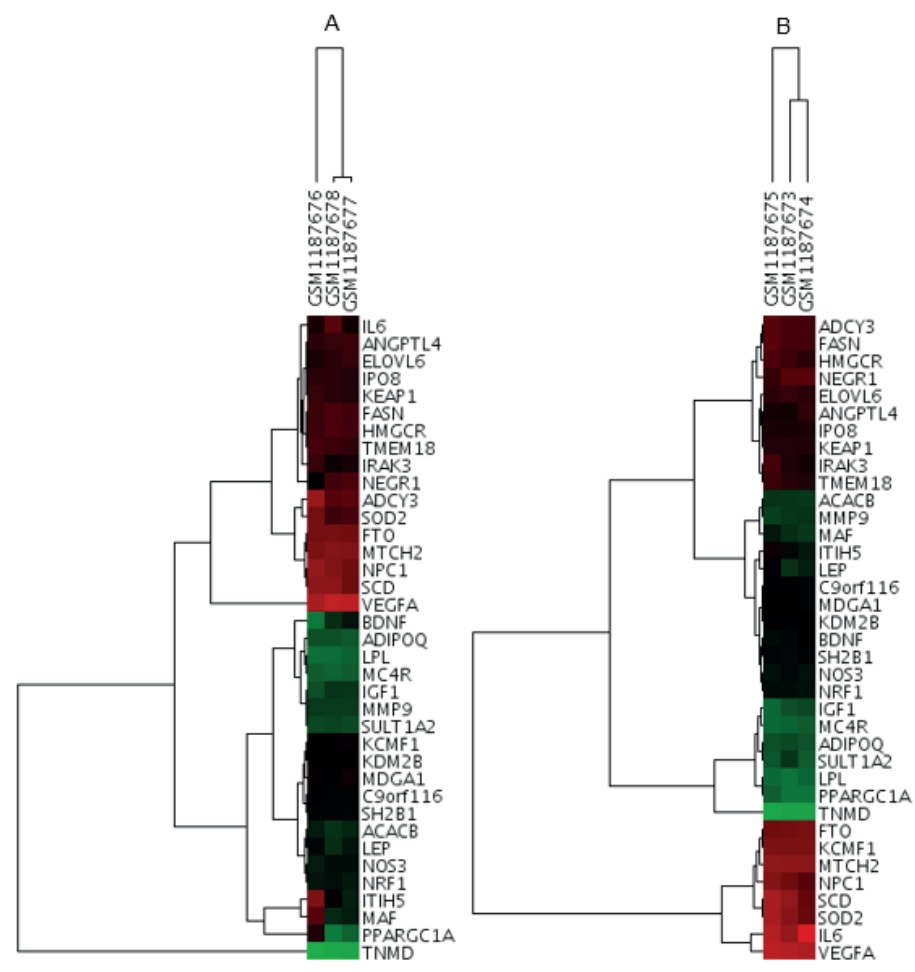

Figura 5. Heat map realizado para los grupos control (A) y obesidad $(B)$ utilizando los z-score de valores de expresión obtenidos del estudio de Oñate y colaboradores (25), utilizando el software Cytoscape 3.2.

sultado importante y que confirma hallazgos bioquímicos previos fue la sobrexpresión del gen de IL6 en las células troncales, provenientes de individuos obesos, incluidos en el análisis. Este hallazgo permite su postulación como biomarcador potencial para un diagnóstico clínico proteómico, debido a que su expresión fue estadísticamente significativa en las células troncales de tejido adiposo blanco de personas obesas. La mayor abundancia de secuencias CpG y Alu, de 20-40 Kpb de la región del genoma humano en la cual se localizan estos genes, sugiere indirectamente la existencia de un posible mecanismo de regulación epigenética por metilación de las CpG localizadas en los promotores de genes asociados en personas obesas. También se sugiere que el mecanismo de regulación de los genes evaluados podría ser por metilación de las islas $\mathrm{CpG}$ ubicadas en sus promotores. Previamente, se han reportado potenciales interacciones entre el ambiente y mecanismos epigenéticos que regulan la expresión de genes asociados con el incremento del IMC y la obesidad.
También se ha determinado una regulación epigenética en el gen FTO que codifica una ADN desmetilasa (34) y en el gen MC4R. Dicha regulación reduce la metilación a causa de la acción a largo plazo de una dieta alta en grasas (35). Este efecto, en conjunto con la acetilación histónica mediada por el receptor gamma de proliferación de peroxisomas -PPARy (36) - sobre los genes POMC (37) y LEP (38), remarcan la importancia de la metilación del $\mathrm{ADN}$ en los promotores de estos genes que se caracterizan por una riqueza de islas $\mathrm{CpG}$, los cuales son potenciales blancos de metilación mC5".

Es importante mencionar las proteínas que resultaron con mayor número de interacciones físicas están involucradas en diferentes procesos y vías metabólicas, diferencialmente reguladas. Una de ellas es el NRF1, proteína implicada en el metabolismo de lípidos en el que su sobreexpresión se relaciona con la imposibilidad de ganar peso (39). De otra parte, el FASN, una enzima que participa de procesos de lipogénesis y cuya expresión en tejido adiposo está relacionada con la acumulación de grasa visceral, incremento de la IL6, leptina y RBP4 circulatoria, lo que sugiere un rol central de las rutas lipogénicas en la relación entre las consecuencias del exceso de energía y el desarrollo de obesidad y diabetes tipo 2 (40).

Otra interacción importante fue la de VEGFA con su receptor VEFGR2 (KDR). Previamente se ha demostrado que, durante la expansión de grasa en personas obesas, la vascularización del tejido adiposo es insuficiente para mantener la normoxia tisular, lo que genera una hipoxia local que puede conllevar a una expresión alterada de adipocinas, reclutamiento de macrófagos proinflamatorios y resistencia a la insulina, una de las patologías asociados con la obesidad (41).

El presente análisis confirmó la importancia del gen que codifica para el IL6 y su interacción con el ILR6. Además, se determinó que el gen IL6 tuvo una mayor expresión en tejido adiposo de personas obesas, en comparación con el tejido de las del grupo de control. Lo anterior lo hace un potencial biomarcador de obesidad, que podría estudiarse a futuro en personas con obesidad, incluyendo un rango más amplio de edades que permita determinar si el IL6 se sobreexpresa incluso en la niñez. En el estudio de Sindhu y sus colaboradores (42), se demostró por medio de técnicas inmunohistoquímicas, RT-PCR y microscopía confocal, que la obesidad es un modulador positivo de la expresión de los genes IL6 e ILR6 en tejido adiposo, lo cual podría ser un mecanismo que contribuya a la inducción de inflamación metabólica. Esta interleuki- 
na es secretada principalmente por adipocitos, especialmente del tejido adiposo visceral, de dos o tres veces más IL-6, en comparación con el tejido adiposo subcutáneo (43). En la obesidad, parece que el estado inflamatorio se origina a partir de estas células, que son activadas por macrófagos M1, los cuales, a su vez, producen citocinas proinflamatorias como TNF- $\alpha$ e IL-6, lo que produce una conexión entre obesidad, inflamación y resistencia a la insulina (44-45).

Se ha encontrado relación del gen FTO con la predisposición a la diabetes y se ha demostrado que modula el IMC (46) y el apetito (47). Además, los estudios realizados por Melhorn y sus colaboradores (48) y Cyrus y sus colaboradores (49) reportaron que variantes en el gen FTO aumentan el riesgo de obesidad debido a un mal procesamiento del sistema nervioso, en cuanto a la saciedad, lo que aumenta la ingesta de comida. Se ha reportado que niveles bajos de FTO en ratones conducen, entre otros efectos, a una reducción significativa del tejido adiposo y masa corporal baja. Por otro lado, el gen NEGR1 codifica para una proteína miembro de la superfamilia de inmunoglobulinas sobreexpresada en el hipotálamo, donde parece que modula el número de sinapsis en neuronas. En este sentido, nuestros resultados aportan una evidencia fuerte de que el gen NEGR1 sería buen candidato funcional en la obesidad, especialmente, si se tiene en cuenta el origen neurológico de esta enfermedad (50).

En nuestro estudio se determinó que las categorías GO más importantes se asociaron con procesos metabólicos alterados en la obesidad. Es así como el proceso metabólico de lipoproteínas es esencial para la correcta metabolización de grasas, colesterol y glúcidos ingeridos (51), cualquier alteración en este proceso podría, junto con otros factores, conllevar a la mala asimilación y posterior acumulación de estos en el cuerpo y al desarrollo de sobrepeso. Otra categoría GO importante fue los procesos que ocurren en el ciclo de los ácidos tricarboxílicos, conocido como embudo del metabolismo, en el que se catabolizan, entre otros, ácidos grasos para la correspondiente producción de energía para la célula (52), además de algunos intermediarios que se convierten en la base de moléculas como la glucosa, ácidos grasos y aminoácidos no esenciales. De otra parte, la activación de las MAP-quinasas y la cascada JNK puede darse por el exceso de especies reactivas de oxígeno (ROS), generadas, a su vez, por la elevada acumulación de lípidos $(53,54)$.
Comprender las complejas interacciones entre la alimentación y la salud es de gran importancia para promover el desarrollo de intervenciones nutricionales más eficientes. que promuevan el bienestar y que puedan reducir los factores de riesgo para enfermedades crónicas no trasmisibles asociadas con la obesidad y que promueven una la alteración de la homeóstasis metabólica. Los resultados obtenidos validan la importancia de la aplicación de herramientas bioinformáticas para poder encontrar evidencias sobre la expresión diferencial tejido específica y las interacciones funcionales que ocurren entre genes, las cuales contribuyen a un estado metabólico normal. La simulación computacional de resultados de experimentos de micromatrices de ADN, consignados en distintas bases de datos y el empleo de plataformas ómicas que se emplearon en este trabajo, abren un nuevo camino para abordar la obesidad como un evento de múltiples causas que genera alteraciones importantes en la expresión de genes claves en el metabolismo energético y cuyo manejo debe incluir nuevos enfoques desde las ciencias ómicas y la bioinformática.

\section{Conflicto de intereses}

Los autores declaran no tener conflictos de interés con respecto al presente artículo.

\section{Referencias}

1. Heianza Y, Qi L, Gene-Diet Interaction and Precision Nutrition in Obesity. Int J Mol Sci. 2017;18(4). P ii.

2. Del Pozo C, Calvo RM, Vesperinas-García G, Gómez-Ambrosi J, Frühbeck G, Rubio MA et al. Expression Profile in Omental and Subcutaneous Adipose Tissue from Lean and Obese Subjects. Repression of Lipolytic and Lipogenic Genes. Obes Surg. 2011; 21: 633-43.

3. Qi Q, Chu AY, Kang JH, Jensen MK, Curhan GC, et al. Sugar-sweetened beverages and genetic risk of obesity. N Engl J Med. 2012 Oct 11;367(15): 1387-96.

4. Brunkwall L, Chen Y, Hindy G, Rukh G, Ericson U, et al. Sugar-sweetened beverage consumption and genetic predisposition to obesity in 2 swedish cohorts. Am. J. Clin. Nutr. 2016; 104: 809-15.

5. Olsen NJ, Angquist L, Larsen SC, Linneberg A, Skaaby T, et al. Interactions between genetic variants associated with adiposity traits and soft drinks in relation to longitudinal changes in body weight and waist circumference. Am. J. Clin. Nutr. 2016; 104: 816-26.

6. Qi Q, Chu AY, Kang JH, Huang J, Rose LM, et al. Fried food consumption, genetic risk, and body mass index: 
Gene-Diet interaction analysis in three us cohort studies. BMJ. 2014; 348: g1610.

7. Tyrrell J, Wood AR, Ames RM, Yaghootkar H, Beaumont $\mathrm{RN}$, et al. Gene-obesogenic environment interactions in the uk biobank study. Int. J. Epidemiol. 2017; 46(2): 559-575.

8. Ng M, Fleming T, Robinson M, Thomson B, Graetz N, et al. Global, regional, and national prevalence of overweight and obesity in children and adults during 1980-2013. A systematic analysis for the global burden of disease study 2013. Lancet. 2014, 384: 766-81.

9. WHO. Obesity and overweight. Fact sheet. Consultado: Octubre de 2017. Disponible en: http://www.who.int/ mediacentre/factsheets/fs311/en/

10. Yang Q, Xiao T, Guo J, Su Z. Complex Relationship between Obesity and the Fat Mass and Obesity Locus. Int $\mathrm{J}$ Biol Sci. 2017; 13(5): 615-62.

11. Park JH, Kim SH, Lee MS, Kim MS. Epigenetic modification by dietary factors: Implications in metabolic syndrome. Mol Aspects Med. 2017; 54: 58-70

12. Qi L, Cho YA. Gene environment interaction and obesity. Nutr Rev. 2008; 66(12): 684-94.

13. Finkelstein EA, Khavjou OA, Thompson H, Trogdon JG, Pan L, et al. Obesity and severe obesity forecasts through 2030. Am J Prev Med. 2012; 42(6): 563-70.

14.Choi B, Schnall P, Dobson M, Yang H, Baker D, et al. Socioecological framework for research on work and obesity in diverse urban transit operators based on gender, race, and ethnicity. Ann Occup Environ Med. 2017; 29: 15.

15. Coppin G. The anterior medial temporal lobes: Their role in food intake and body weight regulation. Physiol Behav. 2016; 167: 60-70.

16. Horstmann A, Fenske WK, Hankir MK. Argument for a non-linear relationship between severity of human obesity and dopaminergic tone. Obes Rev. 2015 Oct; 16(10): 821-30.

17. Horstmann A. It wasn't me; it was my brain-Obesity-associated characteristics of brain circuits governing decisionmaking. Physiol Behav. 2017; 176: 125-33.

18. Ahima RS. Adipose tissue as an endocrine organ. Obesity (Silver Spring) 2006; 14(Suppl 5): 242S-249S.

19. Rosen ED, Spiegelman BM. Adipocytes as regulators of energy balance and glucose homeostasis. Nature. 2006; 444: 847-53.

20. Tilg H, Moschen AR. Adipocytokines: mediators linking adipose tissue, inflammation and immunity. Nat Rev Immunol. 2006; 6: 772-83.

21. Lumeng $C N$, Saltiel AR. Inflammatory links between obesity and metabolic disease. J Clin Invest. 2011; 121: 2111-7.

22. Henrichot E, Juge-Aubry CE, Pernin A, Pache JC, Velebit $\mathrm{V}$, et al. Production of chemokines by perivascular adipose tissue: a role in the pathogenesis of atherosclerosis? Arterioscler Thromb Vasc Biol. 2005; 25: 2594-9.

23. Lago F, Dieguez C, Gomez-Reino J, Gualillo O. Adipokines as emerging mediators of immune response and inflammation. Nat Clin Pract Rheumatol. 2007; 3: 716-24.

24. Campbell K, Foster-Schubert KE, Makar KW, Kratz M, Hagman D, et al. Gene expression changes in adipose tis- sue with diet- and/or exercise-induced weight loss. Cancer Prev Res (Phila). 2013; 6(3): 217-31.

25. Oñate B, Vilahur G, Camino S, Díez A, Ballesta C, et al. Stem cells isolated from adipose tissue of obese patients show changes in their transcriptomic profile that indicate loss in stemcellness and increased commitment to an adipocyte-like phenotype. BMC Genomics. 2013; 14(625): 1-12.

26. Gabrielson E, Berg K, Anbazhagan R. Functional genomics, gene arrays, and the future of pathology. Mod Pathol. 2001; 14(2): 1294-9.

27. Pollack JR. A Perspective on DNA Microarrays in Pathology Research and Practice. Am J Pathol. 2007; 171(2): 375-85.

28. Barquissau V, Ghandour RA, Ailhaud G, Klingenspor M, Langin D, Amri EZ, Pisani DF. Control of adipogenesis by oxylipins, GPCRs and PPARs. Biochimie. 2017; 136: 3-11.

29. Poudyal H, Brown L. Stearoyl-CoA desaturase: a vital checkpoint in the development and progression of obesity. Endocr Metab Immune Disord Drug Targets. 2011; 11(3): 217-31.

30. Chambless LE, Folsom AR, Sharrett AR, Sorlie P, Couper $\mathrm{D}$, et al. Coronary heart disease risk prediction in the Athero-sclerosis Risk in Communities (ARIC) study. J Clin Epidemiol. 2003; 56: 880-890.

31. Musaad S, Haynes EN. Biomarkers of Obesity and Subsequent Cardiovascular Events Epidemiol Rev. 2007; 29: 98-114.

32. Venner A, Lyon M, Doyle-Baker P. Leptin: A potential biomarker for childhood obesity? Clinical Biochemistry. 2006; 39(11): 1047-56.

33. Shannon P, Markiel A, Ozier O, Baliga NS, Wang JT, et al. Cytoscape: A software environment for integrated models of biomolecular interaction networks. Genome Res. 2003; 13(11): pp. 2498-504.

34. Gerken T, Girard CA, Tung YC. The obesity-associated FTO gene encodes a 2-oxoglutarate-dependent nucleic acid demethylase. Science. 2007; 318(5855): 1469-72.

35. Widiker S, Karst S, Wagener A, Brockmann GA. High-fat diet leads to a decreased methylation of the Mc4r gene in the obese BFMI and the lean B6 mouse lines. J Appl Genet. 2010; 51(2): 193-7

36. Choy JS, Wei S, Lee JY, Tan S, Chu S, et al. DNA methylation increases nucleosome compaction and rigidity. J ethylation pattern of leptin promoter in rats. J Physiol Biochem.Am Chem Soc. 2010; 132: 1782-3.

37. Plagemann A, Harder T, Brunn M. Hypothalamic proopiomelanocortin promoter methylation becomes altered by early overfeeding: an epigenetic model of obesity and the metabolic syndrome. J Physiol. 2009; 587 (pt 20): 4963-76.

38. Milagro FI, Campion J, Garcia-Diaz DF, Goyenechea E, Paternain L, et al. High fat diet-induced obesity modifies the $\mathrm{m}$ 2009; 65: 1-9.

39. Hirotsu Y, Higashi C, Fukutomi T, Katsuoka F, Tsujita T, et al. Transcription factor NF-E2-related factor 1 impairs 
glucose metabolism in mice. Genes to Cells. 2014; 19 : 650-65.

40. Berndt J, Kovacs P, Rushke K, Kloting N, Fasshauer M, et al. Fatty acid synthase gene expression in human adipose tissue: association with obesity and type 2 diabetes. Diabetologia. 2007; 50(7): 1472-80.

41. Makki K, Froguel P, Wolowczuk, I. Adipose Tissue in Obesity-Related Inflammation and Insulin Resistance: Cells, Cytokines, and Chemokines. ISRN Inflammation. 2013; 2013: 139-239.

42. Sindhu S, Thomas R, Shihab P, Sriraman D, Behbehani $\mathrm{K}$, Ahmad R. Obesity Is a Positive Modulator of IL-6R and IL-6 Expression in the Subcutaneous Adipose Tissue: Significance for Metabolic Inflammation. PLoS One. 2015; 10(7): e0133494.

43. El-Kadre L, Tinoco A. Interleukin-6 and obesity: the crosstalk between intestine, páncreas and liver. Curr Opin Clin Nutr Metab Care. 2013; 16(5): 564-8.

44. Bressler J, Pankow J, Coresh J, Boerwinkle E. Interaction between the NOS3 gene and Obesity as a determinant of risk of type 2 Diabetes: The Atherosclerosis risk in communities study. PLoS One. 2013; 8(11): e79466.

45. Elias I, Franckhauser S, Ferré T, Vilà L, Tafuro S, et al. Adipose tissue overexpression of vascular endothelial growth factor protects against diet-induced obesity and insulin resistance. Diabetes. 2012; 61(7): 1801-13.

46. Grunnet L, Nilsson E, Ling C, Hansen T, Pedersen O, et al. Regulation and function of FTO mRNA expression in human skeletal muscle and subcutaneous adipose tissue. Diabetes. 2009; 58(10): 2402-08.

47. Klöting N, Schleinitz D, Ruschke K, Berndt J, Fasshauer $\mathrm{M}$, et al. Inverse relationship between obesity and FTO gene expression in visceral adipose tissue in humans. Diabetologia. 2008; 51(4): 641-7.

48. Melhorn S, Askren M, Chung W, Kratz M, Bosch T, Tyagi $\mathrm{V}$ et al. FTO genotype impacts food intake and corticolimbic activation. Am J Clin Nutr. 2018; 107(2): 145-54.

49. Cyrus C, Ismail M, Chathoth S, Vatte C, Hasen M, Al Ali A. Analysis of the Impact of Common Polymorphisms of the FTO and MC4R Genes with the Risk of Severe Obesity in Saudi Arabian Population. Genet Test Mol Biomarkers. 2018; 22(3): 170-7.

50. Fischer J, Kock L, Emmerling C, Vierkotten J, Peters T, et al. Inactivation of the Fto gene protects from obesity. Nature. 2009;458: 894-8.

51. Walley A, Jacobson P, Falchi M, Bottolo L, Andersson J, et al. Differential co-expression analysis of obesity-associated networks in human subcutaneous adipose tissue. Intl $\mathrm{J}$ Obes. 2012; 36(1): 137-47.

52. Hegele R. Plasma lipoproteins: genetic influences and clinical implications. Nat Rev Genet. 2009;10(2): 109-21.

53. Owen O, Kalhan S, Hanson R. The key role of Anaplerosis and Cataplerosis for citric acid cycle function. J Biol Chem. 2002; 227: 30409-12.

54. Qatanani M, Lazar M. Mechanisms of obesity-associated insulin resistance: many choices on the menu. Genes \& Development. 2007; 21: 1443-55. 